\title{
Questes
}

\section{Faire de l'histoire : éléments bibliographiques}

François Wallerich, Pauline Bouchaud et Mélanie Fougre-Lévêque

\section{(2) OpenEdition}

\section{Journals}

\section{Édition électronique}

URL : http://journals.openedition.org/questes/4429

DOI : 10.4000/questes.4429

ISSN : 2109-9472

\section{Éditeur}

Les Amis de Questes

\section{Édition imprimée}

Date de publication : 20 juin 2017

Pagination : 131-136

ISSN : 2102-7188

\section{Référence électronique}

François Wallerich, Pauline Bouchaud et Mélanie Fougre-Lévêque, «Faire de l'histoire : éléments bibliographiques », Questes [En ligne], 36 | 2017, mis en ligne le 02 juillet 2017, consulté le 15 septembre 2020. URL : http://journals.openedition.org/questes/4429 


\section{Éléments bibliographiques}

Cette bibliographie n'a pas vocation à l'exhaustivité ; elle reprend essentiellement les références utilisées dans le numéro.

\section{Généralités}

GuENEE, Bernard, «Y a-t-il une historiographie médiévale ? », Revue historique, vol. 258, 1977, p. 261-275.

-, Histoire et culture historique dans l'Occident médiéval, Paris, Aubier, 2011 [1980].

L'Historiographie médiévale en Europe. Actes du colloque organisé par la Fondation Européenne de la Science au Centre de Recherches Historiques et Juridiques de l'Université Paris I du 29 mars au $1^{\text {er }}$ avril 1989, dir. Jean-Philippe GENET, Paris, Éditions du CNRS, 1991.

LACroIX, Benoît, L'Historien au Moyen Âge, Montréal/Paris, Institut d'études médiévales/ Vrin, 1971.

Grundriss der romanischen Literaturen des Mittelalters, vol. XI, t. 1, La Littérature historiographique des origines à 1500, dir. Hans Ulrich GUMBRECHT, Ursula LiNKHEER, Peter-Michael SPANGENBERG, Heidelberg, Winter, 1986-1987, 3 vol.

Le Métier d'historien au Moyen Âge. Études sur l'historiographie médiévale, dir. Bernard GuENEE, Paris, Publications de la Sorbonne, 1977.

\section{Figures d'historiens au travail}

COLlard, Franck, Un Historien au travail à la fin $d u X V^{e}$ siècle : Robert Gaguin, Genève, Droz, 1996.

DelClos, Jean-Claude, Le Témoignage de Georges Chastellain, historiographe de Philippe le Bon et de Charles le Téméraire, Genève, Droz, 1980.

Dubrasquet-Pardo, Marie-Madeleine, Alfonso de Palencia, historien. Études sur les Gesta hispaniensia, Villeneuve-d'Ascq, Presses universitaires du Septentrion/Atelier national de reproduction des thèses, 2002.

GuENEE, Bernard, Comment on écrit l'histoire au XIII siècle. Primat et le Roman des Roys, éd. Jean-Marie MoEglin, Paris, Éditions du CNRS, 2016.

Guyot-Bachy, Isabelle, Le Memoriale historiarum de Jean de Saint-Victor. Un historien et sa communauté au début du XIV siècle, Turnhout, Brepols, 2000.

GuYotJEAnnin, Olivier, Salimbene de Adam : un chroniqueur franciscain, Turnhout, Brepols, 1995.

Heullant-Donat, Isabelle, «Entrer dans l'Histoire. Paolino da Venezia et les prologues de ses chroniques universelles », Mélanges de l'École française de Rome, Moyen Âge-Temps modernes, vol. 105, $\mathrm{n}^{\circ}$ 1, 1993, p. 381-442. 
IANZITI, Gary, Writing History in Renaissance Italy: Leonardo Bruni and the uses of the past, Cambridge/Londres, Harvard University Press, 2012.

Jodogne, Pierre, Jean Lemaire de Belges, écrivain franco-bourguignon, Bruxelles, Palais des Académies, 1972.

LAMARrigue, Anne-Marie, Bernard Gui (1261-1331). Un historien et sa méthode, Paris, Champion, 2000.

Mironneau, Paul, «Éloge de la curiosité. Aymeric de Peyrac (vers 1340-1406)», Cahiers de Fanjeaux, vol.35, Église et Culture en France méridionale (XII ${ }^{e}$ XIV siècle), 2000, p. 149-183.

Otto von Freising, Rahewin, Conradus sacrista. Geschichtsschreiber des 12. Jahrhunderts in Freising. Beiträge zum 850. Todesjahr Bischof Ottos von Freising 2008, dir. Ulrike GöTZ, Freising, Verlag des Historichen Vereins, 2010.

Paulmier-Foucart, Monique et Duchenne, Marie-Christine, Vincent de Beauvais et le Grand Miroir du Monde, Turnhout, Brepols, 2004.

RECH, Régis, Géraud de Frachet : l'engagement d'un historien au XIII siècle. Édition de sa Chronique universelle, Thèse de diplôme d'archiviste-paléographe, Paris, École nationale des chartes, 1993.

Sigebert de Gembloux, dir. Jean-Paul STRAUS, Turnhout, Brepols, 2015.

Sot, Michel, Un Historien et son église au $X^{e}$ siècle : Flodoard de Reims, Paris, Fayard, 1993.

VON DEN BRINCKEN, Anna-Dorothee, «Martin von Troppau », dans Geschichtsschreibung und Geschichtsbewusstsein im späten Mittelalter, dir. Hans PATZE, Sigmaringen, Thorbecke, 1987, p. 155-193.

\section{Genres historiques}

ARNALDI, Girolamo, «Annali, cronache, storie», dans Lo Spazio letterario del Medioevo, 1.Il Medioevo latino, t. II, vol. I, La Produzione del testo, dir. Guglielmo Cavallo, Claudio Leonardi, Enrico Menstò, Rome, Salerno, 1993, p. 463-513.

DUFOURNET, Jean, «Commynes et l'invention d'un nouveau genre historique », Mémoires de la société d'histoire de Comines-Warneton et de la région, $\mathrm{n}^{\circ} 18$, 1988, p. 57-72.

GUENEE, Bernard, «Histoires, annales, chroniques. Essai sur les genres historiques au Moyen Âge », Annales. Économies, Sociétés, Civilisations, vol. 4, 1973, p. 9971016.

-, «Histoire et Chronique. Nouvelles réflexions sur les genres historiques au Moyen Âge », dans La Chronique et l'Histoire au Moyen Âge, Colloque des 24 et 25 mai 1982 organisé par le Département d'études médiévales de l'Université de Paris-Sorbonne, dir. Daniel PoIRION, Paris, Presses de l'Université de ParisSorbonne, 1984, p. 3-12.

Liber, Gesta, histoire : écrire l'histoire des évêques et des papes, de l'Antiquité au XXI $I^{e}$ siècle, éd. François BoUgARD et Michel Sot, Turnhout, Brepols, 2009. 
Neve De Roden, Anne-Catherine de, «Les Mémoires de Jean de Haynin: des "mémoires", un livre », Les Lettres romanes (hors série), "À l'heure encore de mon escrire». Aspects de la littérature de Bourgogne sous Philippe le Bon et Charles le Téméraire, dir. Claude THIRY, 1997, p. 31-52.

Sot, Michel, Gesta episcoporum, gesta abbatum, Turnhout, Brepols, 1981.

VAN Houts, Elisabeth M. C., Local and Regional Chronicles, Turnhout, Brepols, 1995.

\section{Écriture de l'histoire}

Auctor et Auctoritas. Invention et conformisme dans l'écriture médiévale. Actes du colloque de Saint-Quentin-en-Yvelines (14-16 juin 1999), dir. Michel ZIMMERMANN, Paris, École des chartes, 2001.

L'Autorité du passé dans les sociétés médiévales, dir. Jean-Marie SANSTERRE, Rome/Bruxelles, École française de Rome/Institut historique belge de Rome, 2004.

Bien dire et bien aprandre, $\mathrm{n}^{\circ} 22$, Histoire et Roman, textes réunis par Catherine Croizy-NAQuet et Philippe LogIE, 2004.

Certeau, Michel de, L'Écriture de l'histoire, Paris, Gallimard, 2002 [1975].

Courroux, Pierre, L'Écriture de l'histoire dans les chroniques françaises (XII ${ }^{e}$ $X V^{e}$ siècle), Paris, Classiques Garnier, 2016.

Doudet, Estelle, Poétique de George Chastelain (1415-1475). Un cristal mucié en un coffre, Paris, Champion, 2005.

L'Écriture de l'histoire au Moyen Âge. Contraintes génériques, contraintes documentaires, dir. Étienne ANHEIM, Pierre CHASTANG, Francine MORA-LEBRUN et Anne Rochebouet, Paris, Classiques Garnier, 2015.

GUENEE, Bernard, «L'histoire entre l'éloquence et la science. Quelques remarques sur le prologue de Guillaume de Malmesbury à ses Gesta regum Anglorum », Comptesrendus de l'Académie des inscriptions et belles-lettres, 1982, p. 357-370.

Historiographies, concepts et débats, vol. 2, dir. Christian DELACROIX, François Dosse, Patrick GARCIA, Paris, Gallimard, 2010.

JodoGne, Pierre, «La rhétorique dans l'historiographie bourguignonne », dans Culture et Pouvoir au temps de l'Humanisme et de la Renaissance. Actes du congrès de Marguerite de Savoie, Annecy-Chambéry-Turin, 29 avril-4 mai, dir. Louis TerreauX, Paris/Genève, Champion/Slatkine, 1978, p. 51-69.

MARChEllo-NiziA, Christiane, "L'historien et son prologue : forme littéraire et stratégies discursives », dans La Chronique et l'Histoire au Moyen Âge, Colloque des 24 et 25 mai 1982 organisé par le Département d'études médiévales de l'Université de Paris-Sorbonne, éd. Daniel PoIRION, Paris, Presses de l'Université de Paris-Sorbonne, 1984, p. 13-25.

Poétique de la chronique. L'écriture des textes historiographiques au Moyen Âge (péninsule ibérique et France), éd. Amaia ARIZALETA, Toulouse, CNRS-Université de Toulouse-Le-Mirail, 2008. 
Les Prologues médiévaux, Actes du Colloque international organisé par l'Academia Belgica et l'École française de Rome avec le concours de la F.I.D.E.M. (Rome, 2628 mars 1998), éd. Jacqueline HAMESSE, Turnhout, Brepols, 2000.

VeYne, Paul, Comment on écrit l'histoire, Paris, Éditions du Seuil, 1996 [1971]. 


\section{Enjeux de l'écriture de l'histoire}

DALY, Kathleen, «"Pour vraye congnoissance avoir". Historical culture and polemic in the French royal Chambre des comptes in Paris in the fifteenth century ", Nottingham medieval studies, vol. 49, 2005, p. 142-189.

GUENEE, Bernard, «Histoire, mémoire, écriture. Contribution à une étude des lieux communs », Comptes-rendus de l'Académie des inscriptions et belles-lettres, vol. 123, n 3, 1983, p. 441-456.

LECUPPRE-DESJARDIN, Élodie, «Maîtriser le temps pour maîtriser les lieux : la politique historiographique bourguignonne dans l'appropriation des terres du Nord au XV $\mathrm{VV}^{\mathrm{e}}$ siècle ", dans Écritures de l'histoire (XIV ${ }^{e}-X V I^{e}$ siècle). Actes du colloque $d u$ Centre Montaigne, Bordeaux, 19-21 septembre 2002, dir. Danièle BOHLER et Catherine Magnien Simonin, Genève, Droz, 2005, p. 371-384.

Moeglin, Jean-Marie, «La vérité de l'histoire et le moi du chroniqueur», dans La Vérité. Vérité et crédibilité : construire la vérité dans le système de communication de l'Occident (XIII'-XVII siècle). Actes de la conférence organisée à Rome en 2012 par SAS en collaboration avec l'École française de Rome, dir. Jean-Philippe GENET, Paris/Rome, Publications de la Sorbonne/École française de Rome, 2015, p. 521-538.

TAYLOR, John, The Use of medieval chronicles, Londres, Historial association, 1965.

\section{Diffusion, réception, public}

Accès aux textes médiévaux de la fin du Moyen Âge au XVIII siècle. Actes de colloque, dir. Michèle Gueret-Laferte et Claudine Poulouin, Paris, Champion, 2012.

Coleman, Joyce, Public Reading and the reading public in late medieval England and France, Cambridge, Cambridge University Press, 1996.

Godfrey of Viterbo and his readers. Imperial tradition and universal history in late medieval Europe, dir. Thomas FOERSTER, Farnham, Ashgate, 2015.

GUENEE, Bernard, «La culture historique des nobles. Le succès des Faits des Romains (XIII ${ }^{\mathrm{e}}-\mathrm{XV}^{\mathrm{e}}$ siècles) », dans La Noblesse au Moyen Âge. XI $-X V^{e}$ siècles. Essais à la mémoire de Robert Boutruche, dir. Philippe CONTAMINE, Paris, PUF, 1976, p. 261288.

-, «Histoire d'un succès », dans Les Grandes Chroniques de France. Reproduction intégrale en fac-similé des miniatures de Fouquet. Manuscrit français 6465 de la Bibliothèque nationale de Paris, dir. François AVRIL, Marie-Thérèse GoussET et Bernard GuENEE, Paris, Lebaud, 1987, p. 81-138.

GuYot-BACHY, Isabelle et MoEglin, Jean-Marie, «Comment ont été continuées les Grandes Chroniques de France dans la première moitié du XIV siècle », Bibliothèque de l'École des chartes, vol. 163, n 2, p. 385-433.

Haug, Hélène, Fonctions et Pratiques de la lecture à la fin du Moyen Âge. Approche sociolittéraire $d u$ discours sur la lecture en milieu curial d'après les sources narratives françaises et bourguignonnes (1360-1480), Thèse de doctorat, Louvainla-Neuve, Université catholique de Louvain, 2013. 
L'Histoire et les nouveaux publics dans l'Europe médiévale (XIII ${ }^{e}-X V^{e}$ siècles). Actes du colloque international organisé par la Fondation européenne de la science à la Casa de Velasquez, Madrid, 23-24 avril 1993, éd. Jean-Philippe GENET, Paris, Publications de la Sorbonne, 1997.

Lectures françaises de la fin du Moyen Âge. Petite anthologie commentée de succès littéraires, éd. Frédéric DuVAL, Genève, Droz, 2007.

RuDY, Kathryn M., «Dirty books. Quantifying patterns of use in medieval manuscripts using a densitometer », Journal of historians of Netherlandish art, vol. 2, n ${ }^{\circ}$ 1-2, 2010, URL : http://www.jhna.org/index.php/past-issues/volume-2-issue1-2/129-dirty-books, page consultee le 6 juin 2017.

SPIEGEL, Gabrielle M., The Chronicle Tradition of Saint-Denis. A survey, Brookline/Leyden, Classical folia editions, 1978.

TISCHLER, Matthias M., Einharts Vita Karoli. Studien zur Entstehung, Überlieferung und Rezeption, Hannover, Hahn, 2001, 2 vol.

VAN HoorebeEcK, Céline, «La clientèle des miniaturistes. Des manuscrits enluminés pour quels publics?», dans Miniatures flamandes. 1404-1482, dir. Bernard Bousmanne et al., Paris/Bruxelles, BnF/Bibliothèque royale de Belgique, 2011, p. 81-88.

-, «Du livre au lire. Lectures et lecteurs à l'épreuve des catégorisations sociales », dans Lecteurs, lectures et groupes sociaux au Moyen Âge. Actes de la journée d'étude organisée par le Centre de recherche "Pratiques médiévales de l'écrit" (PraME) de l'Université de Namur et le département des manuscrits de la Bibliothèque royale de Belgique. Bruxelles, 18 mars 2010, dir. Xavier HERMAND, Étienne RENARD et Céline VAn HoOREBEECK, Turnhout, Brepols, 2014, p. 123-131.

-, Livres et Lectures des fonctionnaires des ducs de Bourgogne (ca 1420-1520), Turnhout, Brepols, 2014. 